\title{
Coping with their Children's Illnesses by Mothers Belonging to Double- income Nuclear Families and their Use of Pediatric Emergency Services
}

Chizuko Edagawa', Ikuko Sobue ${ }^{2 *}$

${ }^{1}$ Department of Nursing, Faculty of Health Sciences, Ehime Prefectural University of Health Sciences, Japan

${ }^{2}$ Division of Nursing Science, Graduate School of Biomedical \& Health Sciences, Hiroshima University, Hiroshima 734-8553, Japan

Article Details
Article Type: Research Article
Received date: $13^{\text {th }}$ May, 2017
Accepted date: $10^{\text {th }}$ September, 2017
Published date: $16^{\text {th }}$ September, 2017
"Corresponding Author: Ikuko Sobue, Graduate School of Biomedical \& Health Sciences, Hiroshima University, 1-2-3
Kasumi, Minami-ku, Hiroshima 734-8553, Japan. E-mail: sobue@hiroshima-u.ac.jp
Citation: Edagawa C, Sobue I (2017) Coping with their children's illnesses by mothers belonging to double-income nuclear
families and their use of pediatric emergency services. J Comp Nurs Res Care 2: 113. doi: http://dx.doi.org/jcnrc/2017/113.
Copyright: $\mathbb{0} 2017$, This is an open-access article distributed under the terms of the Creative Commons Attribution License
4.0, which permits unrestricted use, distribution, and reproduction in any medium, provided the original author and source are
credited.

\begin{abstract}
Objective: Among children using emergency medical services, those belonging to nuclear or double-income families account for the majority. This study examined double-income nuclear families' coping with their children's sickness and pediatric emergency service use by them, aiming to reduce such service use in non-emergency cases.
\end{abstract}

Methods: Semi-structured interviews were conducted with 27 mothers, who belonged to double-income nuclear families living in a prefecture, to examine the mother's age, sick child's age, number of children, coping with the child's sickness, and pediatric emergency service use.

Results: Working full-time, most of the mothers belonging to double-income families tended to notice their children's sickness after work. They examined the child's pathological condition based on their parenting experience, and decided whether to use emergency medical services or wait and see. Anxiety in those lacking parenting experience was intensified by the necessity of using nocturnal or holiday medical services and the child's young age, and alleviated by emergency medical service use. Sources of support for the mothers included: the husband, web searches, and a pediatric emergency telephone consultation service; such a service enhanced their sense of security, and provided them with guidance for appropriate medical service use. While feeling secure with their family doctors, the mothers were dissatisfied with nocturnal clinic services, systems and public information regarding doctors on duty on holidays, and long waiting times in hospitals/clinics due to crowdedness.

Conclusion: The results suggest the usefulness of pediatric emergency telephone consultation services for mothers belonging to double-income nuclear families and lacking parenting experience to reduce pediatric emergency service use by them in non-emergency cases.

Keywords: Double-income Nuclear Families, Mothers, Pediatric Emergency Service Use

\section{Introduction}

Infants are particularly vulnerable to infection due to their immunological characteristics. Being anxious over their sickness, their parents use pediatric emergency services $[1,2]$. In the case of sudden sickness or unusual symptoms, parents, facing difficulty in accurately recognizing the child's condition, seek specialized treatment in the early stages $[3,4]$. The reduction of pediatric emergency service use in non-emergency cases is a common challenge for advanced countries [5, 6]. Parents' socioeconomic fragility is a negative factor for such reduction. The rate or frequency of medical service use is high among single parents, young mothers, parents with poor academic profiles or low incomes, and children without siblings [7-10]. On the other hand, extensive parenting experience and the presence of close confidants prevent parents' excessive anxiety over their children's sickness, and lead them to appropriately use emergency medical services [11-14]. In fact, pediatric emergency service use is less frequent among children with 2 or more siblings or living with their grandparents $[10,11]$.

Children belonging to double-income or nuclear families account for the majority of those using emergency medical services [1517]. This is an inevitable result of high rates of nuclear and doubleincome households among the total population. Since the 1990's, the number of double-income households has been higher than that of households consisting of an employed husband and non-working wife (full-time housewife), and the difference between them is timedependently increasing [18]. In 2010, nuclear and double-income households accounted for 75 and $54.9 \%$, respectively, of all those with children younger than 6 years [19]. In the absence of grandparents, parenting and sick child care support resources for nuclear families are limited. They tend to be markedly anxious about the quality of and access to pediatric emergency services [20], and use them even in nonemergency cases [10]. As for double-income families, it is frequently difficult for both parents to visit their family doctor (hospital/clinic) during service hours due to their jobs [15, 21]. Thus, double-income nuclear families are more likely to use emergency medical services in non-emergency cases. Considering their high rate among the total population, they may increase the frequency of pediatric emergency service use in non-emergency cases.

However, to the author's knowledge, reports on double-income nuclear families' coping with their children's sickness or pediatric emergency service use by them have been limited [10]. The clarification of double-income nuclear families' trends in emergency 
medical service use is indispensable for the reduction of pediatric emergency service use in non-emergency cases, as well as the promotion of appropriate medical care for children with severe conditions. To provide a basis for these approaches, this study examined double-income nuclear families' coping with their children's sickness and pediatric emergency service use by them.

\section{Methods}

\section{Study design: A qualitative, descriptive study}

This study is part of a research project, entitled: The examination of child-raising support to promote parents' sense of security towards and appropriate use of pediatric emergency medical care services. From April to May 2011, semi-structured interviews were conducted with 27 mothers, who belonged to double-income nuclear families living in A prefecture, based on the following inclusion criteria: 1) using sick child care services; 2)having a child/children under 6 years of age; 3 ) working full-time, similarly to the husband; 4) and having used pediatric emergency medical care services (during out-ofservice hours). Through the interviews, the mother's age, sick child's age, number of children, status of parenting, coping with the child's sickness, sick child care service use and need for such services, and pediatric emergency service use and need for such services were examined using an interview guide. This study reported the mothers' coping with their children's sickness and their usage of pediatric emergency medical care services.

The mothers were recruited through our website or by putting up posters in 8 sick child care facilities within the prefecture. They were provided with written and oral explanations of: the study objective and methods; freedom to participate in, refuse, and withdraw from the study; and no disadvantageous treatment for those refusing to participate in or cooperate with it, to obtain their written consent. The interviews were conducted in private rooms of 4 public facilities or the researcher's institution in the prefecture for the mothers' convenience. Each mother was interviewed once for approximately 1 hour. With their agreement, their statements during the interviews were recorded. To prevent the identification of individuals, the obtained data were processed using linkable anonymization. The study was approved by the research ethics committee of the researcher's institution (approval number: Heisei22-75).

The mothers' recorded statements were organized as narrative records to extract and encode contents representing their coping with their children's sickness and pediatric emergency service use by them based on the context. Common contents were labelled to create categories and sub-categories based on commonalities. The analytical process was supervised by a researcher specializing in pediatric nursing to ensure sufficient reliability and validity. In the following section, categories, sub-categories, and labels are shown in [ ], <>, and " ", respectively.

\section{Results}

The mean age of the 27 mothers belonging to double-income nuclear families was $34.1 \pm 4.26$. Among them, $21(77.7 \%)$ were regular employees. The sick child's mean age was $3.0 \pm 1.33$, and the mean number of children was $1.9 \pm 0.9$.

\section{Parents' coping with their children's sickness (Table 1)}

[The parent's coping] with the child's sickness was represented by $<$ noticing the child's poor condition $>$, $<$ medical facilities $>$, and $<$ difficulty in using medical services due to work $>$. The mothers tended to notice their children's sickness when picking them up after work or on the way home. Most clinics and hospitals were closed during such hours, as one mother stated: "Hospital services are not available at the time when I pick my child up at the nursery school". Therefore, they used emergency medical services, or visited a hospital the next day. It was also difficult for them to take their children to a hospital during service hours or early due to their jobs, and tended to put off visiting a hospital.

\begin{tabular}{|c|c|c|}
\hline Category & Sub-category & Label \\
\hline \multirow[t]{10}{*}{ The parent's coping } & \multirow[t]{2}{*}{ Noticing the child's poor condition } & I noticed my child's poor condition when I picked him up. \\
\hline & & $\begin{array}{l}\text { I noticed his poor condition when we were on the way } \\
\text { home. }\end{array}$ \\
\hline & \multirow[t]{5}{*}{ Medical facilities } & $\begin{array}{l}\text { Hospital services are not available at the } \\
\text { time when I pick my child up at the nursery school }\end{array}$ \\
\hline & & Until 18:00 (19:00), we visit our family doctor, as usual \\
\hline & & I consult our family doctor by telephone. \\
\hline & & We use emergency medical services. \\
\hline & & We will visit a hospital the next day \\
\hline & \multirow[t]{3}{*}{$\begin{array}{l}\text { Difficulty in using medical } \\
\text { services due to work }\end{array}$} & $\begin{array}{l}\text { It is difficult for me to take my child to a hospital early. As } \\
\text { a result, his condition is worse when we visit it. }\end{array}$ \\
\hline & & $\begin{array}{l}\text { We cannot visit a hospital during service } \\
\text { hours due to my job. }\end{array}$ \\
\hline & & I tend to put off taking my child to a hospital. \\
\hline
\end{tabular}

Table 1. Parents' coping with their children's sickness

\section{Sources of support for sick children(Table 2)}

[Sources of support] for the mothers to cope with their children's sickness included: <husband $>$, <web searches $>$, and the <pediatric emergency telephone consultation service (\#8000)>. They consulted their husbands, and came to themselves when they were told to calm down. They also felt secure with their husbands who helped them care for their sick children. Furthermore, they conducted $<$ web searches $>$ to collect information, aiming to examine the name of the diagnosis, symptoms, the necessity of visiting a hospital, and management methods, or refer to the opinions of people who had been sick. When they were not sure whether to take their children to a hospital, they used the <pediatric emergency telephone consultation service $>$ to obtain advice. They felt relieved with the advice, and decided to take their children to a hospital the next morning. They favorably evaluated such a consultation service, stating: "I actively use these services, because I agree with their attitudes, such as listening to me attentively and answering". 


\begin{tabular}{|c|c|c|}
\hline Categories & Subcategories & Labels \\
\hline \multirow[t]{12}{*}{ Sources of support } & \multirow[t]{3}{*}{ Husband } & I consult my husband \\
\hline & & $\begin{array}{l}\text { I came to myself when my husband told me } \\
\text { to calm down. }\end{array}$ \\
\hline & & $\begin{array}{l}\text { I feel secure with my husband who helps } \\
\text { me care for the child even at midnight }\end{array}$ \\
\hline & \multirow[t]{4}{*}{ Web searches } & $\begin{array}{l}\text { I mainly perform web searches to collect } \\
\text { information }\end{array}$ \\
\hline & & $\begin{array}{l}\text { I examine various issues, such as the name } \\
\text { of the diagnosis and symptoms. }\end{array}$ \\
\hline & & $\begin{array}{l}\text { I examine methods to diagnose and manage } \\
\text { a high fever and diarrhea, as well as the } \\
\text { necessity of taking my child to a hospital. }\end{array}$ \\
\hline & & $\begin{array}{l}\text { I refer to the opinions of people who have } \\
\text { been sick. }\end{array}$ \\
\hline & \multirow[t]{5}{*}{$\begin{array}{l}\text { Pediatric emergency telephone consultation } \\
\text { service }(\# 8000)\end{array}$} & $\begin{array}{l}\text { I somehow managed my child's condition } \\
\text { using the method of care taught by a } \\
\text { consultant, and took him to a pediatric } \\
\text { hospital the next morning. }\end{array}$ \\
\hline & & $\begin{array}{l}\text { I actively use these services, because I } \\
\text { agree with their attitudes, such as listening } \\
\text { to me attentively and answering. }\end{array}$ \\
\hline & & $\begin{array}{l}\text { I have written down } \# 8000 \text { and the mobile } \\
\text { numbers of clinics providing nocturnal } \\
\text { medical services on my calendar. }\end{array}$ \\
\hline & & $\begin{array}{l}\text { I call them anyway, because I also feel } \\
\text { relieved if they say that we do not have to } \\
\text { visit an emergency hospital. }\end{array}$ \\
\hline & & $\begin{array}{l}\text { I called them when I was not sure whether } \\
\text { to take my child to a hospital, as the } \\
\text { pamphlet says. }\end{array}$ \\
\hline
\end{tabular}

\section{Reasons for using/not using emergency medical services} (Table 3)

The mothers' [reasons for using] emergency medical services included: <severe symptoms $>,<$ lack of experience $>$, and $<$ anxiety $>$. Their [reasons for not using] were represented by $<$ based on experience $>$ and $<$ waiting and seeing $>$.

The mothers took their children to an emergency hospital when $<$ severe symptoms $>$ were present. Regarding this, they stated: "I take my child to an emergency hospital when a fever of $40{ }^{\circ} \mathrm{C}$, nausea, or vomiting persists" and "If my child still looks vigorous even with a fever of $39^{\circ} \mathrm{C}$, I will wait and see, but if he becomes exhausted, we visit a facility providing nocturnal medical services". $<$ Lack of experience $>$ was another reason for using emergency medical services, as one mother stated: "Lacking experience, I used to quickly take my first child to an emergency hospital". The mothers' anxiety was intensified by the sick child's young age and the necessity of using nocturnal or holiday medical services. In contrast, it was alleviated by emergency medical service use.

Those who did not use emergency medical services were able to examine the sick child's pathological condition independently based on their experience of caring for such children, and decided to wait and see the situation, as one mother clarified her basis for decisionmaking as follows: "Even when a high fever occurs, it is enough to visit a hospital the next morning if the child can ingest fluids, with a vigorous and stable condition". They also used stored suppositories and cooling patches when observing their children's conditions.

\begin{tabular}{|l|l|l|}
\hline Category & Sub-category & Label \\
\hline Reasons for using & Severe symptoms & $\begin{array}{l}\text { I take my child to an emergency hospital } \\
\text { when a fever of } 400 \text { C, nausea, or vomiting } \\
\text { persists. }\end{array}$ \\
& & $\begin{array}{l}\text { We use emergency medical services when } \\
\text { he suffers from fever and vomiting. }\end{array}$ \\
\hline
\end{tabular}

Table 3. to be Cont... 


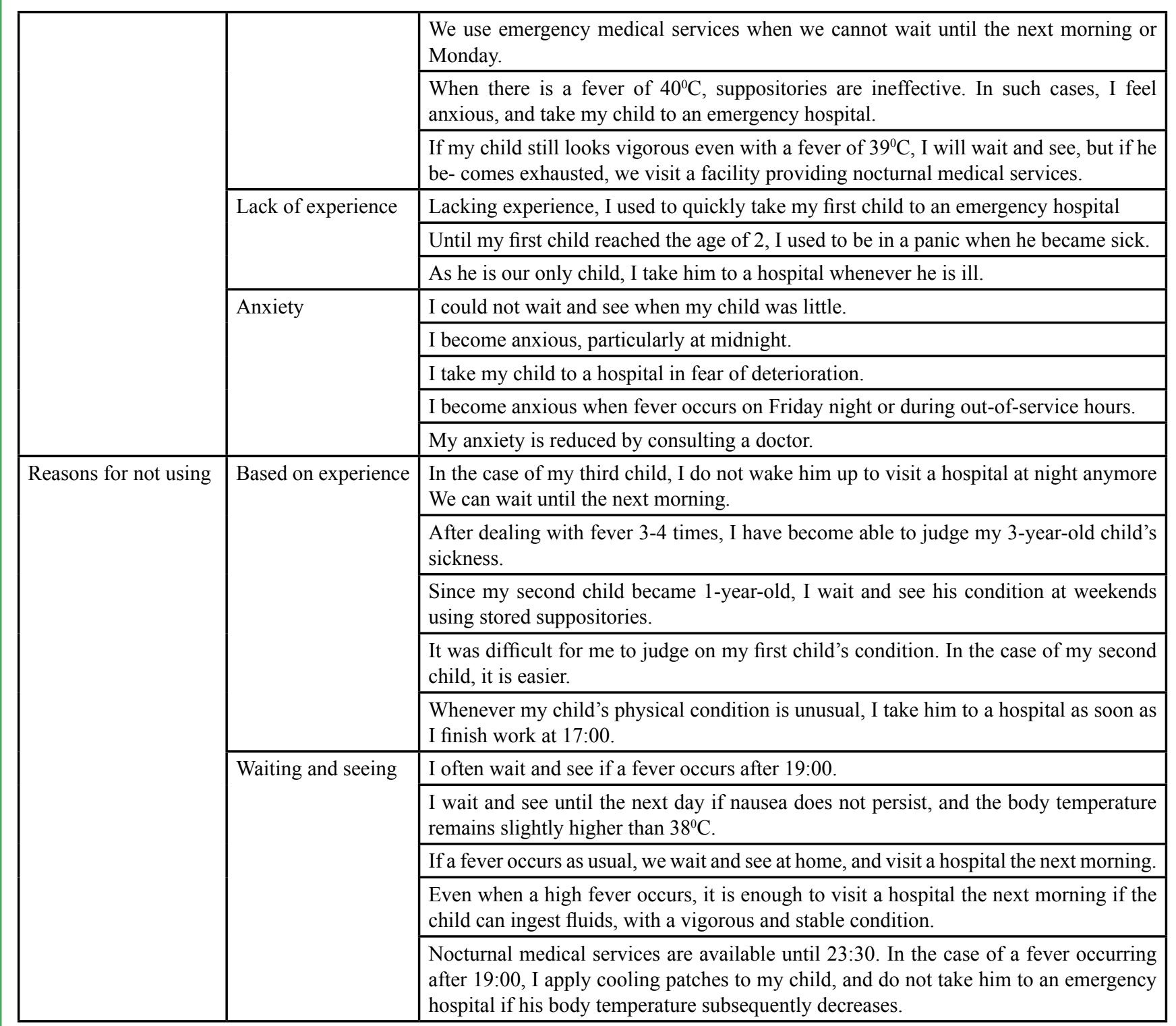

Table 3. Reasons for using/not using emergency medical services

\section{Families' experiences related to emergency medical service use (Table 4)}

The types of emergency medical services used by the mothers were classified into: [family doctor], [nocturnal clinic services], [doctors on duty on holidays], [pharmacy services], and [ambulance services]. [Family doctors] enhanced the mothers' $<$ sense of security $>$ by clearly answering theirquestions, explaining possible symptoms, and showing reliable attitudes ("We can rely on our family doctor who helps us in any situation"). Some mothers tended to $<$ frequently use $>$ [nocturnal clinic services] due to fever or other causes, while revealing their dissatisfaction with such services due to long waiting times and difficulty in clarifying the doctor on duty. They also faced difficulty in confirming the locations of [doctors on duty on holidays], accessing distant hospitals, and using hospital services due to crowdedness, resulting in long waiting times. They needed [pharmacy services], including guidance for appropriate oral medication and suppository use. As for [ambulance services], insufficient services due to hospitals' refusal to accept some pediatric patients are noted.

\begin{tabular}{|l|l|l|}
\hline Category & Sub-category & Label \\
\hline Family doctor & Sense of security & Our family doctor clearly answers my questions. \\
\cline { 3 - 3 } & $\begin{array}{l}\text { With the doctor's explanation of possible symptoms, I can prepare myself to } \\
\text { manage the situation. }\end{array}$ \\
\cline { 3 - 3 } & & We can rely on our family doctor who helps us in any situation. \\
\hline
\end{tabular}

Table 4. to be Cont... 


\begin{tabular}{|c|c|c|}
\hline Noctural clinic services & Frequent Use & $\begin{array}{l}\text { We frequently use such services (fever, vomiting, diarrhea, } \\
\text { or influenza). }\end{array}$ \\
\hline & Long waiting times & Waiting times are too long. \\
\hline & & $\begin{array}{l}\text { We cannot choose the doctor on duty. Some doctors are } \\
\text { unkind. }\end{array}$ \\
\hline & & $\begin{array}{l}\text { When my child's pathological condition is poor, we want to } \\
\text { consult the doctor at once, but we have to wait until 19:30 } \\
\text { when the evening consultation service starts. }\end{array}$ \\
\hline & & $\begin{array}{l}\text { They always treat us kindly with consideration. They also } \\
\text { provide a detailed explanation of care to be received the } \\
\text { next day. We have never experienced unpleasant treatment. }\end{array}$ \\
\hline \multirow[t]{10}{*}{ Doctors on duty on holidays } & Information collection & $\begin{array}{l}\text { I seek such information through newspapers, TV text, and } \\
\text { web searches. }\end{array}$ \\
\hline & & $\begin{array}{l}\text { Information regarding doctors on duty can be collected } \\
\text { through newspapers. I always store such information. }\end{array}$ \\
\hline & & $\begin{array}{l}\text { I have called the doctor on duty several times to confirm the } \\
\text { location of his facility }\end{array}$ \\
\hline & $\begin{array}{l}\text { Judgment on the necessity of medical } \\
\text { consultation }\end{array}$ & $\begin{array}{l}\text { On holidays, it is less burdensome for hospital staff to deal } \\
\text { with patients during the daytime than at night }\end{array}$ \\
\hline & & $\begin{array}{l}\text { On Sundays and national holidays, we basically receive } \\
\text { medical con- sultation. }\end{array}$ \\
\hline & & $\begin{array}{l}\text { I check the doctor on duty to decide whether or not to visit } \\
\text { the hospital on that day. }\end{array}$ \\
\hline & Distance & The hospital is in a remote area. \\
\hline & & We cannot visit distant facilities. \\
\hline & Crowdedness & $\begin{array}{l}\text { The hospital is so crowded that it makes my child even } \\
\text { more exhausted. }\end{array}$ \\
\hline & & We rarely use such services because of long waiting times. \\
\hline \multirow[t]{4}{*}{ Pharmacy services } & Guidance & $\begin{array}{l}\text { They provide an explanation of suppositories and } \\
\text { antipyretics. }\end{array}$ \\
\hline & & $\begin{array}{l}\text { In the beginning, it is difficult to lead children to } \\
\text { appropriately take oral medications without guidance. }\end{array}$ \\
\hline & Inconvenience & Dispensing pharmacies are far \\
\hline & & $\begin{array}{l}\text { It is distressful to take a crying child to an out-of-hospital } \\
\text { pharmacy }\end{array}$ \\
\hline \multirow[t]{2}{*}{ Ambulance services } & Risks & Some hospitals refused to accept my child \\
\hline & & $\begin{array}{l}\text { The pediatric hospital would securely accept my sick child, } \\
\text { but it takes } 1 \text { hour to visit it. }\end{array}$ \\
\hline
\end{tabular}

Table 4. Families' experiences related to emergency medical service use

\section{Discussion}

1. Reasons for using emergency medical services: the mother's insufficient parenting experience and the child's young age

Most of the mothers involved in this study were regular employees working full-time, and tended to notice their children's sickness after work. In such a situation, they had to choose whether to visit the family doctor, use emergency medical services, or wait and see the situation (and visit a hospital the next day). As family doctor services were not available during such hours, the mothers examined the sick child's pathological condition independently based on their experience of caring for such children, and decided whether to use emergency medical services or wait and see the situation. Their decisions were based on the birth order and age. For example, one mother used emergency medical services due to her anxiety "until my first child reached the age of 2". Another mother became able to wait and see her child's condition using stored suppositories "since my second child became 1-year-old". In the case of the third child, they tended to wait until the next morning to visit a hospital.

Thus, the mothers' extensive parenting experience may have enhanced their home nursing skills and health literacy. Conversely, a lack of such experience was associated with poor health literacy, excessive anxiety over the child's pathological condition, and emergency medical service use. In a cross-sectional study involving 14,000 parents, a lower number of children led to more marked anxiety over pediatric emergency services (their quality and accessibility, as well public and private support for them) and more frequent medical service use in non-emergency cases [10]. In a retrospective cohort study involving 1,343,585 ED visits, 57.1\% were shown to be inappropriate (non-emergency) [22]. Inappropriate ED visits were associated with the sick child's young age (0-3 years) and the necessity of using nocturnal or holiday medical services when primary care services were unavailable. Based on these findings, 
it may be important to support mothers lacking parenting experience while improving the availability of hospital/clinic services during out-of-service hours (after work) when parents tend to notice their children's sickness [23], in order to reduce pediatric emergency service use in non-emergency cases.

\section{Sources of support for mothers to cope with their children's sickness}

For the mothers, the husband, web searches, and the pediatric emergency telephone consultation service were main sources of support. Through web searches, they examined the name of the diagnosis, symptoms, the necessity of visiting a hospital, and management methods. They used a pediatric emergency telephone consultation service to learn appropriate methods of care and determine the necessity of visiting a hospital. Such a service enhanced their sense of security, and provided them with guidance for appropriate medical service use.

The pediatric emergency telephone consultation service is a system to consult pediatricians or nurses on methods to appropriately cope with children's sudden sickness during the night-time and on holidays. The service started in all prefectures in 2010 [24], and the total number of service uses was 631,595 in 2014 [25]. Such services reduce medical service use in non-emergency cases by providing reliable parenting support. They also function as medical triage to identify children with severe conditions [26, 27]. The majority of users are the mothers of children aged 0 , followed by those of children aged $0-1$, accounting for more than half [28]. This is consistent with the results of the present study examining pediatric emergency service users. For mothers belonging to double-income nuclear families with difficulty in accessing family doctor services and obtaining parenting support from their parents (the child's grandparents) living separately, pediatric emergency telephone consultation services may be an important source of support. Therefore, it may be necessary to address their limited availability at midnight (currently limited to $40 \%$ ) and during the daytime on holidays (8.5-19\%) and a low connection rate (1 every 5.7-7.3 calls) due to limited telephone networks [29].

In 2016, additional family pediatric service fees were incorporated into the medical insurance system to promote family doctor services, including 24-hour telephone consultation services and health guidance for parents [30]. Being more personalized than \#8000, telephone consultation services provided by family doctors may be more effective to enhance parents'sense of security, and practice appropriate medical triage. In this respect, family doctors may be another important source of support for double-income nuclear families, contributing to the reduction of pediatric emergency service use in non-emergency cases.

\section{Availability of medical services for double-income nuclear} families

Even if pediatric emergency telephone consultation services appropriately function as a source of support for mothers lacking parenting experience, the availability of hospital/clinic services during out-of-service hours (after work) when parents tend to notice their children's sickness has yet to be improved. In the present study, the mothers were dissatisfied with nocturnal clinic services and systems regarding doctors on duty on holidays, while feeling secure with their family doctors.

As the doctor on duty during the night-time or on holidays varies depending on the day, the insufficient provision of related information intensified the mothers' anxiety. Some of them also noted the inconvenience of confirming the location of his/her facility and risks due to the necessity of visiting distant facilities. These problems may be resolved by appropriately providing public information. For example, in the emergency medical service system operated by municipalities, information covering issues, such as multiple doctors on duty on holidays and their specialties, is extensively provided in each secondary medical zone [31].

As the information provided through newspapers, TV text data, or public relations brochures is limited to the names and telephone numbers of emergency hospitals due to limited space, measures to improve users' convenience, such as providing public information that facilitates access to online information from mobile phones or other terminals, and incorporating navigation functions (maps), may be necessary.

As issues related to out-of-hospital prescriptions, the time needed to access the nearest dispensing pharmacy and the usefulness of explanations of oral medication and suppositories were noted by the mothers. Currently, a large number of municipalities collaborate with community-based pharmaceutical associations to designate pharmacies on duty on holidays $[32,33]$. In addition to this system, telephone consultation services provided by family pharmacists/ pharmacies during out-of-service hours and dispensing services during the night-time and on holidays are being promoted [34]. In a previous study involving pharmacies $(\mathrm{N}=701), 75.5 \%$ established a system to provide nocturnal and holiday services, and more than $60 \%$ actually provided them over the last 1 month. It is expected that the development of family pharmacies will also improve the quality of guidance for parents to appropriately use emergency medical services in the future.

For the mothers belonging to double-income families, it was difficult to appropriately manage the situation when noticing their children's sickness after work. They also faced difficulty in accessing medical services on weekdays. Their jobs forced them to put off taking their children to a hospital until their conditions became worse. In another study involving 561 working mothers, $30.5 \%$ stated that the sense of difficulty in taking leave from work was the most marked (the highest level=7) when their children were sick [15]. In the case of doubleincome nuclear families, the mother tends to take the sick child to a hospital (higher than $60 \%$ ), or take leave from work to care for him/her (higher than 80\%) [35]. They take leave from work to care for their sick children 3.8 times/year (6.3 days/year) [36]. Based on the national policy, leave from work to care for pre-school children with sickness is paid [37]. It is also possible to apply for half-day leave, but the total number of days is limited to 5 days/year; this is lower than the amount of leave actually taken by mothers, indicating that it remains difficult for working mothers to take sufficient leave from work to care for their sick children even when they can visit a hospital during service hours.

As a study limitation, it was difficult to analyze double-income nuclear families, with factors promoting medical service use in nonemergency cases, poor health literacy, poor academic profiles, low incomes, and the absence of siblings incorporated, due to a small sample size. Variations in anxiety and pediatric emergency service use among mothers due to systems also remained unclear. In order to reduce pediatric emergency service use in non-emergency cases, it may be necessary to examine double-income nuclear families, focusing on additional risk factors such as a lack of parenting experience, as children belonging to such families account for the majority of service users. Furthermore, the usefulness of pediatric emergency telephone consultation services should also be confirmed based on users' characteristics to promote the provision of public information regarding such services and their use, and consequently reduce emergency service use by non-emergency pediatric patients.

\section{Conclusion}

Working full-time, most mothers belonging to double-income families tended to notice their children's sickness after work. They examined the child's pathological condition based on their parenting experience, and decided whether to use emergency medical services or wait and see. Therefore, their anxiety was more marked when 
their first children was sick. The pediatric emergency telephone consultation service enhanced mothers'sense of security, and provided them with guidance for appropriate medical service use.

The results suggest the usefulness of pediatric emergency telephone consultation services for mothers belonging to doubleincome nuclear families and lacking parenting experience to reduce pediatric emergency service use by them in non-emergency cases.

\section{Acknowledgements}

We are very grateful to all those who participated in this study

\section{Funding}

This study was funded by a Grant-in-Aid for scientific research expenses of the Japan society for the Promotion of Science (22659412) and (16H05586).

\section{Conflict of Interests}

The authors have no conflicting interest in this study

\section{Reference}

1. Yagihashi T, Sato S, Kojima N, Tomotsugi N, Shitaoka R, et al. (2011) Maternal anxiety and psychosocial problems in the pediatric emergency services. J Child Health 70: 298-304.

2. Mishina H, Takayama JI, Aizawa S, Tsuchida N, Sugama S (2011) Association between maternal childrearing anxiety and pediatric emergency department visits. J Child Health 70: 3945.

3. Tan Y (2007) Analysis of parents' thoughts regarding their judgments and responses when their children were suddenly taken ill: parents' fear, peace of mind, coping behavior and demands of government in the free-answer question. Jpn J Public Health 54: 711-722.

4. Edagawa C, Inoshita H, Sasaki M (2004) Mothers' daily observation of the health state of their infants/small children and coping behavior for children's illness. Nurs J Kagawa Med Univ 8: 45-52.

5. Parry YK, Ullah S, Raftos J, Willis E (2016) Deprivation and its impact on non-urgent Paediatric Emergency Department use: are Nurse Practitioners the answer? J Adv Nurs 72: 99106.

6. Moskop JC, Sklar DP, Geiderman JM, Schears RM, Bookman KJ (2009) Emergency department crowding, part 1 - concept, causes, and moral consequences. Ann Emerg Med 53: 605-611.

7. Brousseau DC, Hoffmann RG, Nattinger AB, Flores G, Zhang Y, et al. (2007) Quality of primary care and subsequent pediatric emergency department utilization. Pediatrics 119: 1131-1138.

8. Kennedy TJ, Purcell LK, LeBlanc JC, Jangaard KA (2004) Emergency department use by infants less than 14 days of age. Pediatr Emerg Care 20: 437-442.

9. Phelps K, Taylor C, Kimmel S, Nagel R, Klein W, et al. (2000) Factors associated with emergency department utilization for nonurgent pediatric problems. Arch Fam Med 9: 1086-1092.

10. Wier LM, Yu H, Owens PL, Washington R (2013) Overview of children in the emergency department, 2010: statistical brief \#157. AHRQ 1-12.

11. Sobue I, Tanimoto K, Ohashi J, Itoh S (2013) Status of pediatric emergency service use based on the number of children and birth order. J Jpn Assoc Emerg Nurs 15: 13-22.

12. Oberlander TF, Pless IB, Dougherty GE (1993) Advice seeking and appropriate use of a pediatric emergency department. Am J Dis Child 147: 863-867.

13. Gross GJ, Howard M (2001) Mothers' decision-making processes regarding health care for their children. Public Health Nur 18: 157-168.
14. Vinelli NF, Mannucci C, Laba NI, del Vecchio L, Valerio A, et al. (2011) Non-urgent 16 emergency department visits at a children's hospital. Arch Argent Pediatr 109: 8-13.

15. Tanaka T, Ishii H, Uchiyama Y, Ichikawa K (2006) The investigation of concerning reasons of emergency pediatric visit and support at child sickness. J Jpn Soc Emerg Paediatr 5: 131134.

16. Okiyama Y, Nagayama S, Azuma A, Nakasone T, Okawa M, et al. (2010) The utilization of pediatric emergency care of young parents in Okinawa island. The Okinawa J Child Health 37: 5964.

17. Horwitz SM, Horwitz RI, Morgenstern H. (1993) Maternal employment, maternal care and pediatric visits for minor acute illnesses. J CUII Epldemiol 46: 981-986.

18. Ministry of Health, Labour and Welfare (2011) The Annual Health, Labour and Welfare Report 2011.

19. Statistics Japan (2017) The national sensus in 2010.

20. Shimobiraki, C (2005). Determinants of anxiety in parents for children's emergency medicine in Japan. Jpn J Public health 52: 349-355.

21. Arai K, Ota C, Yasunari T, Sakashita R, Katada N (2012) Difficulties faced by working mothers in the event that their children require medical care owing to sudden illness. UH CNAS, RINCPC Bull 19: 83-96.

22. Vedovetto A, Soriani N, Merlo E, Gregori D (2014) The burden of inappropriate emergency department pediatric visits: Why Italy needs an urgent reform. Health Serv Res 49: 1290-1305.

23. Matsumura T, Ohshige K, Tsuchida K, Mizushima S, Tochikubo $\mathrm{O}$ (2007) The increasing use of pediatric emergency facilities in the evening. Pediatr Emerg Care 23: 142-147.

24. Ministry of Health, Labor and Welfare (2017) Pediatric emergency telephone consultation service.

25. Central Social Insurance Medical Council (2017) Outpatient care (Part 1).

26. Committee about the social support of the emergency pediatric service, The Japanese Society of Child Health (2007) The meaning of emergency pediatric service telephone consultation for social support.

27. Yoshizawa J (2016) Measures to generalize the digital pediatric emergency telephone consultation service manual. J Jpn Pediatr Assoc 51: 93-95.

28. Fukui M, Kino M, Kobayashi H, Kageyama M, Toyota Y (2009) The sum of the telephone consultation for pediatric emergency in Osaka prefecture during last three years. Jpn J Pediatr 62: 909-916.

29. The Facility Planning Division Health Policy Bureau Ministry of Health, Labour and Welfare (2013) The telephone consultation for pediatric emergency (\#8000).

30. Health Insurance Bureau Ministry of Health, Labour and Welfare (2016) Effects of fixed basic outpatient consultation fees on the family doctor system.

31. Kagawa Prefecture (2017) Mecical Care Net Sanuki.

32. Sagawa, K (2011) Future perspectives on pharmacy management (Part 6 - Final Report): Establishment of community-based pharmacies and approaches for their successful future. Dispensing Inf 17: 1221-1225.

33. The Hiroshima prefecture branch of Japan Pharmaceutical Association (2017) Holiday duty drugstore.

34. Central Social Insurance Medical Council (2015) Dispensing fee (part 2). 
35. Endo M (2003) The division of household labor in doubleincome families: Nuclear families with both parents working full-time with children in nursery schools. Kyoto J Sociol 11: 57-72.

36. Tanihara M, Abe H, Mori T, Okada K (2010) Parents' response to their sick child and the current status of sick-child-care support needs. Kawasaki Med Welf J 19: 411-418.

37. Ministry of Health, Labor and Welfare (2017) Outline of the revised child care and family care leave law and revised equal employment opportunity law. 